\title{
Chemotherapy and Immunotherapy for Tuberculosis
}

\author{
Navdeep Kaur *, Sachin Sharma \\ Sri Sai College of Pharmacy, Manawala, Amritsar-143115, Punjab, India \\ Address for Correspondence: Navdeep Kaur; dnav1222@gmail.com
}

Received:
01.03.2019
Accepted:
25.03.2019
Keywords
Anti-TB Drugs;
Mycobacterium
tuberculosis;
DOTS.

Received:

Accepted:

Keywords

Anti-TB Drugs;

Mycobacterium

DOTS.

\begin{abstract}
Tuberculosis (TB) is a mycobacterium infection which occurs due to Mycobacterium tuberculosis. It is the major infectious diseases with a mortality rate of nearly two million mostly in developing countries every year. This increases occurrence of resistance of Mycobacterium tuberculosis strains to the most effective antibiotics which serves as a major factor contributing to the current TB epidemic. This situation has lead to a rise in the need of the development of chemotherapy and immunotherapy. Chemotherapy is unique two phase therapy which consist of first line and second line drugs. The drugs like Isoniazid, Ethambutol etc. (First line) and ofloxacin, kanamycin etc. (Second line) are commonly used. These drugs used more effective and easily available. The first line drugs are more effective than the second line drugs. Combination drug therapy is desirable as a single drug is ineffective in the cases of MDR-TB. The commonly known treatment of TB is DOTS. The immunotherapy show good result in MDR-TB. The use of immunotherapy with Interlukin-2, Interferon and Interlukin-7 as an adjacent to drug treatment may improve success rate of MDR- TB shortens the treatment time for drug sensitive TB and improves the immunity by enhancing Mycobacterium tuberculosis elimination to prevent the recurrence of disease. () 2019 iGlobal Research and Publishing Foundation. All rights reserved.
\end{abstract}

Cite this article as: Kaur, N.; Sharma, S. Chemotherapy and Immunotherapy for Tuberculosis. Indo Global J. Pharm. Sci., 2019; 9(2Suppl.): 150. DOI: http://doi.org/10.35652/IGJPS.2019.92S48 .

Indo Global Journal of Pharmaceutical Sciences( ISSN 2249 1023; CODEN- IGJPAI; NLM ID: 101610675) indexed and abstracted in CrossRef (DOI Enabling), UGC CARE Journal List, EMBASE(Elsevier), National Library of Medicine (NLM) Catalog, ResearchGate, Publons, CAS (ACS), Index Copernicus, Google Scholar and many more. For further details, visit http://iglobaljournal.com

This is a special issue as an outcome of 'RAPSCON-2019' sponsored by APTI and organized by Sri Sai College of Pharmacy, Manawala, Amritsar, Punjab, India. Relaxation offered in journal format. 